\title{
SOCIAL NETWORKING：FRIEND OR FOE? A STUDY OF CYBERBULLYING AT A UNIVERSITY CAMPUS
}

\author{
Jamie L. Pinchot, Robert Morris University,pinchot@rmu.edu \\ Karen L. Paullet, Robert Morris University, paullet@rmu.edu
}

\begin{abstract}
This study investigates the experiences and perceptions of 168 undergraduate college students regarding cyberbullying, including a focus on the role of social networking in cyberbullying incidents. Personal experiences of students were explored, including experiences that students have had as victims of cyberbullying and as witnesses of cyberbullying incidents involving others. Research found that while most cyberbullying incidents occur during high school, cyberbullying is continuing at the university level. In addition, social networking sites such as Facebook, along with text messaging, are the primary technologies being used for online harassment.
\end{abstract}

Keywords: cyberbullying, online harassment, social networking and Facebook

\section{INTRODUCTION}

Social networking and other digital communication methods such as text messaging are becoming a daily way of life for today's youth. While these technologies provide many benefits and conveniences for young people, an unintended consequence of their use is cyberbullying. Most people, at some point in their life, have had experiences with schoolyard bullies. Today's youth experiences bullying that not only affects them at school, but also follows them home in the form of online harassment [11]. Social networking sites, text messaging, and other popular digital communication technologies are available online and now via mobile devices which many students keep with them at all times. Cyberbullying, just like traditional bullying, has been linked with a variety of problems including depression and low self-esteem [13].

Students who have been bullied in high school could traditionally expect to have a fresh start and escape the bullying when they moved on to university. Today's social networking sites, such as Facebook, now allow friends (and bullies) to follow students from high school to university [2]. While many studies have looked at cyberbullying issues and concerns at the high school level, there is a definite lack of literature studying cyberbullying incidents at the university level.

\section{RELATED LITERATURE}

\section{Social Networking and Cyberbullying Among Adolescents and Teens}

A 2011 study conducted by Consumer Reports revealed some alarming findings about children using Facebook. Of the 20 million minors who used Facebook in 2011, 7.5 million that is equal to more than one-third of users, were younger than 13 years of age. One million children were harassed, threatened, or subjected to other forms of cyberbullying on Facebook in 2011 [1].

Cyberbullying statistics among youth can vary depending on the age of the group and how the meaning of cyberbullying is defined. A 2010 study conducted by Hinduja and Patchin defined cyberbullying as when someone "repeatedly makes fun of another person online or repeatedly picks on another person through email or text message or when someone posts something about another person that they don't like." According to the definition provided to the 4,400 participants, $20 \%$ of $11-18$ year old students indicated being a victim of cyberbullying. Additional findings showed that $10 \%$ of the students had been both a victim and an offender [5].

The Pew Internet Research Center's 2011 study on teen cruelty and social network sites revealed that $90 \%$ of socialmedia using teens who have witnessed online cruelty say that they have ignored mean behavior online. Fifty-two 


\section{Issues in Information Systems \\ Volume 14, Issue 2, pp.174-181, 2013}

percent of parents worry that their child will be bullied via social network sites while 1 in 6 parents know that their child already has been bullied via a social network site [6].

Patchin \& Hinduja [8] conducted a study in 2006 which was then replicated in 2009 to determine adolescent online behaviors with a focus on MySpace. The study revealed three prominent trends that included MySpace profile abandonment, restricted access, and posting of personal/private information. First, the researchers found that $44 \%$ of profiles were considered invalid or abandoned in the 2009 study as compared to $6 \%$ in 2006 . Additionally, $50 \%$ of the remaining profiles in 2009 compared to $9 \%$ in 2006 had not been updated in over one year [8]. Secondly, the researchers determined that more users set their profiles to "private" in $2009(37 \%)$ as compared to $2006(11.5 \%)$ [8]. It appears that those who have retained their MySpace profiles have chosen to increase their profiles security by restricting access to individuals outside of their circle. The third trend found in this study was that youths who maintained profiles were less likely to post personal information such as pictures of their friends in swimsuits/underwear or swear words in their profile and in their comments. In 2009, the study found that $85 \%$ of adolescents had restricted access to their profiles which is up from $39 \%$ in 2006 [8]. This could be an indication that adolescents are becoming aware of the need to stay safe online.

A 2010 study conducted by Li [7] collected data about cyberbullying from 269 middle school and high school students from five different Canadian schools. The study focused on student perceptions about cyberbullying as well as actions after cyberbullying occurs. Li [7] found that over $40 \%$ would do nothing if they were a victim of cyberbullying, and only 1 in 10 would inform an adult about the incident.

Harris Interactive [3] conducted a study for the National Crime Prevention Council (NCPC) on teens and cyberbullying using a representative sample of 824 middle and high school students. Approximately $43 \%$ of teens reported that they were a victim of cyberbullying. Forty-six percent of high school students experienced cyberbullying compared to $35 \%$ of middle school students and cyberbullying was more prevalent among females. Seventy-one percent of the respondents believe that the most effective way to prevent cyberbullying is for victims to block the communication, followed by $62 \%$ who simply refuse to pass along cyberbullying messages.

According to Perez [9], 32\% of online teens have experienced some form of harassment via the Internet. Of those teens, $15 \%$ have had private material forwarded without their permission, $13 \%$ have received threatening messages and $6 \%$ have had embarrassing photos posted without their permission.

\section{Social Networking and Cyberbullying Among College Undergraduates}

Zacchilli and Valerio [14] conducted a study to examine the knowledge and prevalence of cyberbullying in college. Participants were asked to report about their use of the Internet and technology. Results of the study indicated that college students use the Internet most often for social networking and schoolwork. Approximately, 23\% of students reported being cyberbullied in high school, while $9 \%$ indicated cyberbullying in college. Victims were asked if they talked to someone about being cyberbullied. Seventeen percent did not talk to anyone, $23 \%$ talked to a parent, $20 \%$ talked to siblings $26 \%$ talked to a friend and $11 \%$ sought help from a counselor. Students were also asked if they tried to stop the cyberbullying from occurring. For victims, $15 \%$ stated that no one tried to stop them from being bullied over the Internet. Lastly $43 \%$ of participants knew someone who had been a victim of cyberbullying with $29 \%$ reporting that the person was a friend.

Henson, Reyns and Fischer [4] conducted a study in 2011 to examine the link between online social network activity, privacy and victimization. A total of 914 college students responded to the survey. The researchers found that users who engage in precarious behaviors while using social network sites, such as opening numerous accounts or adding strangers as friends, were more likely to become a victim of a cyber-related crime. Protecting the privacy of users has become an area of concern for providers. The study revealed a significant relationship between online victimization and gender, number of social network accounts, number of updates, adding strangers as friends and the use of profile trackers of those using Facebook and MySpace. Female users were almost twice as likely as males to become a victim of a cyber-related incident. Approximately $42 \%$ of social network users experience some form of online victimization [4]. 


\section{Issues in Information Systems \\ Volume 14, Issue 2, pp.174-181, 2013}

Walker, Sockman, and Koehn [12] conducted an exploratory study of 120 undergraduate University students on cyberbullying. The study revealed that $54 \%$ of respondents knew someone that had been a victim of cyberbullying. The primary methods used to cyberbully a victim were Facebook, 56\%, cell phones, $45 \%$, and instant messaging $43 \%$. Eleven percent of students indicated that they were bullied at the University level. The most frequent technologies used to bully students at the University level were Facebook, $64 \%$, followed by cell phones, 43\%, and instant messaging. Students were permitted to choose more than one option for which they were bullied which is why the percentages do not add up to $100 \%$. Students revealed that in almost $50 \%$ of instances they were cyberbullied by a classmate. Of the students bullied, $30 \%$ of victims received messages from someone pretending to be someone other than themselves, and 31\% said the bullies friended people on Facebook in order to obtain personal information about the victim.

\section{PURPOSE OF STUDY}

The literature examined above makes it clear cyberbullying is a growing problem not only among adolescents and teens, but also at the university level. While general education and awareness programs about cyberbullying are now being targeted toward elementary schools, middle schools, and high schools, there appears to be a lack of awareness and concern about cyberbullying at the university level. This exploratory study sought to examine the perceptions of college students about cyberbullying, as well as their experiences with cyberbullying as either a victim or a witness. In addition, the relationship between social networking and cyberbullying was explored.

The following research questions were addressed:

RQ1: What experiences have students had with cyberbullying at the university level?

RQ2: Does social networking play a role in cyberbullying for university students?

\section{RESEARCH METHODOLOGY}

This exploratory study examined the perceptions and experiences of college students regarding cyberbullying, and their relationship with social networking use. A survey was administered to a convenience sample of 168 college undergraduates at a mid-Atlantic university. Participants included in the sample were all enrolled in a core university course at the time of the survey between January and March 2013. Students from this course were chosen purposefully to capture a cross-section of university students from different major courses of study. Prior to survey administration, a pilot test was conducted with 42 undergraduates to test the validity and reliability of the survey questions.

The survey questionnaire consisted of 22 questions. First, participants were asked for their age and gender. Next, they were asked if they are a member of a social networking site. Much of the literature has shown that a great deal of cyberbullying takes place on social networks $[4,12]$. If they were a member of a social network, they were asked to indicate which site(s) they use, how much time they spend on social networks daily, and their most important reason for using social networking sites. All participants were then asked what they considered to be the disadvantages of social networking sites.

The next section of the questionnaire addressed victimization, asking participants if they had ever been cyberbullied. If they were cyberbullied, they were also asked when the incident took place, either during high school or college, and if the bullying was currently happening. Additional questions asked participants to indicate the types of communication utilized by the cyberbully, including email, social networks, text messaging, blogs, and chat rooms. Participants were also asked if they knew the cyberbully offline, and in what capacity, including: friend, online acquaintance, from work, from school, or former boyfriend/girlfriend. In addition, participants were asked if they reported the incident of cyberbullying. The survey also asked those who reported the incident whether they had received help.

Another section addressed participant experiences as witnesses of cyberbullying via social networking. If participants had witnessed cyberbullying via a social networking site, they were asked to indicate their normal 


\section{Issues in Information Systems \\ Volume 14, Issue 2, pp.174-181, 2013}

response, including: joining in, reading/viewing but not participating, leaving the online environment, standing up to the bully, or reporting the incident to someone who would be able to help the victim.

Students were also asked about their overall awareness and knowledge level regarding cyberbullying. The survey asked whether their high school or university offered programs or lectures to inform students about cyberbullying. Participants were also asked about their awareness of legal consequences for cyberbullying. Lastly, they were asked to provide open-ended ideas for the prevention of cyberbullying.

\section{FINDINGS}

Of the 168 undergraduate students surveyed, $62 \%$ were male and $38 \%$ were female. The age range of participants spanned from 18 to 45, with a significant skew toward the younger side of the range, with both a mean and median age of 19 . The majority of the sample, $82 \%$, were aged 18-20. Participants aged $21-30$ made up $17 \%$ of the sample, and the remaining $1 \%$ included participants aged $31-45$. The younger ages of the participants studied can be largely attributed to the fact that the survey was administered as a convenience sample to sections of a core university course normally taken by underclassmen.

\section{How University Students are Affected by Cyberbullying}

Twenty-one percent of the 168 students surveyed responded that they had been a victim of cyberbullying, either while they were in high school, or while they have been at university. Of the $21 \%$ who had been victims, the majority, $97 \%$, indicated that the incident(s) occurred during high school. A chi square test was performed (chisquare $=164.968, d f=2, \mathrm{p}<.000$ ), indicating a statistically significant relationship between being a victim of cyberbullying and having the bullying occur during the student's time in high school. This finding is highly supported in the literature and by the education and awareness programs that have been launched across the country to address cyberbullying at the high school and primary school levels. However, $9 \%$ of the participants in our sample indicated that they were currently being cyberbullied, which shows that cyberbullying at the university level is occurring, and may be a growing problem. Just over half of the victims, $54 \%$, responded that they reported the incident of cyberbullying (by telling someone about it) when it occurred. Only $37 \%$ of these students who did report or tell about the incident stated that they received help.

Students were also asked about other experiences with cyberbullying, not as a victim of a bully, but rather as a witness to cyberbullying occurring to someone else on a social networking site. More than half of the students surveyed, $66 \%$, indicated that they personally know a victim of cyberbullying. Students who had witnessed cyberbullying on a social networking site were asked about how they would normally respond to such a situation. The majority of students, $64 \%$, indicated that they would passively watch the cyberbullying occur - reading or viewing posts but not participating. This result in and of itself indicates a major problem. If more witnesses would take action when they see a cyberbullying incident, more victims could perhaps receive much-needed help. Some of the student participants reported that they would take action; twenty-two percent indicated that they would stand up to the bully, and $21 \%$ answered that they would report the incident to someone who could help the victim. Eighteen percent replied that they would leave the online environment to remove themselves from the situation. A minority, $2 \%$, of students admitted that they would actually join in on the bullying. These results are shown in Figure 1. Note that students were permitted to select more than one response. 


\section{Issues in Information Systems \\ Volume 14, Issue 2, pp.174-181, 2013}

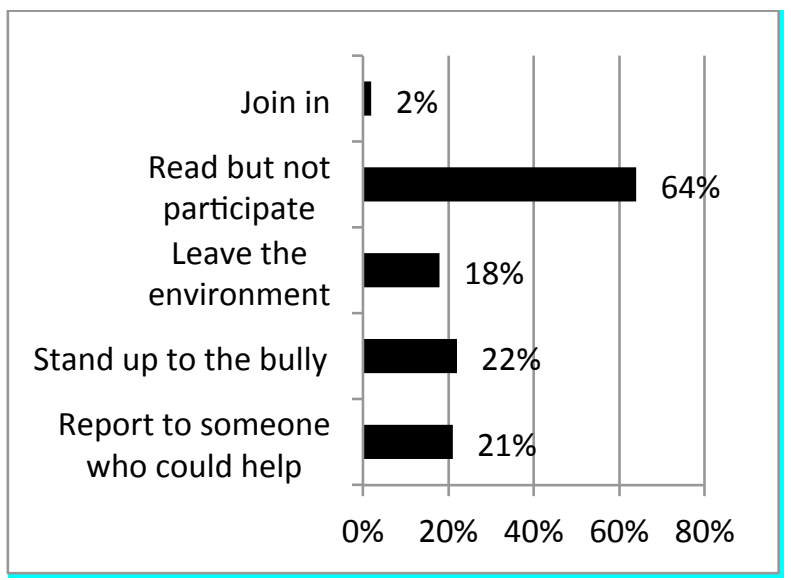

Figure 1. Percentage of student responses to the witnessing of cyberbullying

Students were asked to respond to the following statement: "Cyberbullying is a normal part of using technology. There is nothing anyone can do to stop it." Five percent of the respondents indicated they "Strongly Agree" with this statement, and 44\% indicated that they "Agree." Thirty percent answered that they "Disagree" and 21\% said "Strongly Disagree." Overall, more than half of the students, $51 \%$, expressed disagreement with this statement while $49 \%$ indicated agreement. This near-even split of responses may indicate that students are generally confused or unsure about what, if anything can be done to prevent cyberbullying. When asked for ideas to help prevent cyberbullying, 11 participants wrote in that the only way to prevent cyberbullying is to get rid of social media or abstain from using it.

\section{Social Networking and Cyberbullying at the University Level}

Social networking sites have often been a vehicle for harassment by cyberbullies $[4,9]$. The majority of respondents, $96 \%$, indicated that they were a member of a social networking site. Of those $96 \%, 91 \%$ use Facebook, $62 \%$ use Twitter, $62 \%$ use YouTube, and 23\% indicated use of a social network not listed.

Other than MySpace, which has fallen out of general favor over the past number of years, social network usage among the other selected sites is quite high. The "other" category made up a relatively large percentage, $23 \%$, indicating that the current study may not have included some pertinent social networking sites currently in use. Students indicated a high daily usage rate for social networks, with $32 \%$ spending $1-2$ hours daily on social networks, 30\% spending 2-4 hours daily, and 7\% spending more than 4 hours daily. The majority, $89 \%$, of respondents using social networks indicated that their most important reason for using social networking sites is to connect with friends. Less than $2 \%$ responded that they use social networks to meet new people. All respondents were asked what they thought were the disadvantages of using social networking sites. Becoming addicted to social networking was cited as a disadvantage by $57 \%$ of the respondents, followed by anonymity (41\%) (not knowing who you might be talking with online) and cyberbullying (35\%). Other responses included: peer pressure (12\%), and staying up late or getting up early to be online (39\%). Ten percent of respondents answered that there are no disadvantages to social networking.

Of the $21 \%$ of participants who indicated that they had been victims of cyberbullying, $97 \%$ were active members of at least one social networking site. The respondents who had been a victim of cyberbullying were also asked about the forms of communication that the cyberbully used to contact them, including email, text messaging, Facebook, Twitter, blogs, chat rooms, and other. The highest responses for respondents who were cyberbullied in high school were Facebook, $85 \%$, and text messaging, $74 \%$, with Twitter following at $18 \%$, email at $9 \%$, blogs at $6 \%$, chat rooms at $3 \%$, and "other" indicated by $6 \%$. Note that participants were permitted to choose more than one form of communication. Respondents who indicated that they are currently being cyberbullied at the university level reported similar high responses for communication via Facebook, 67\%, and text messaging, 67\%. However, 33\% of these students currently being cyberbullied indicated "other," and none of them reported any communication with the cyberbully via email, Twitter, blogs, or chat rooms. Results are depicted in Figure 2. 


\section{Issues in Information Systems}

Volume 14, Issue 2, pp.174-181, 2013

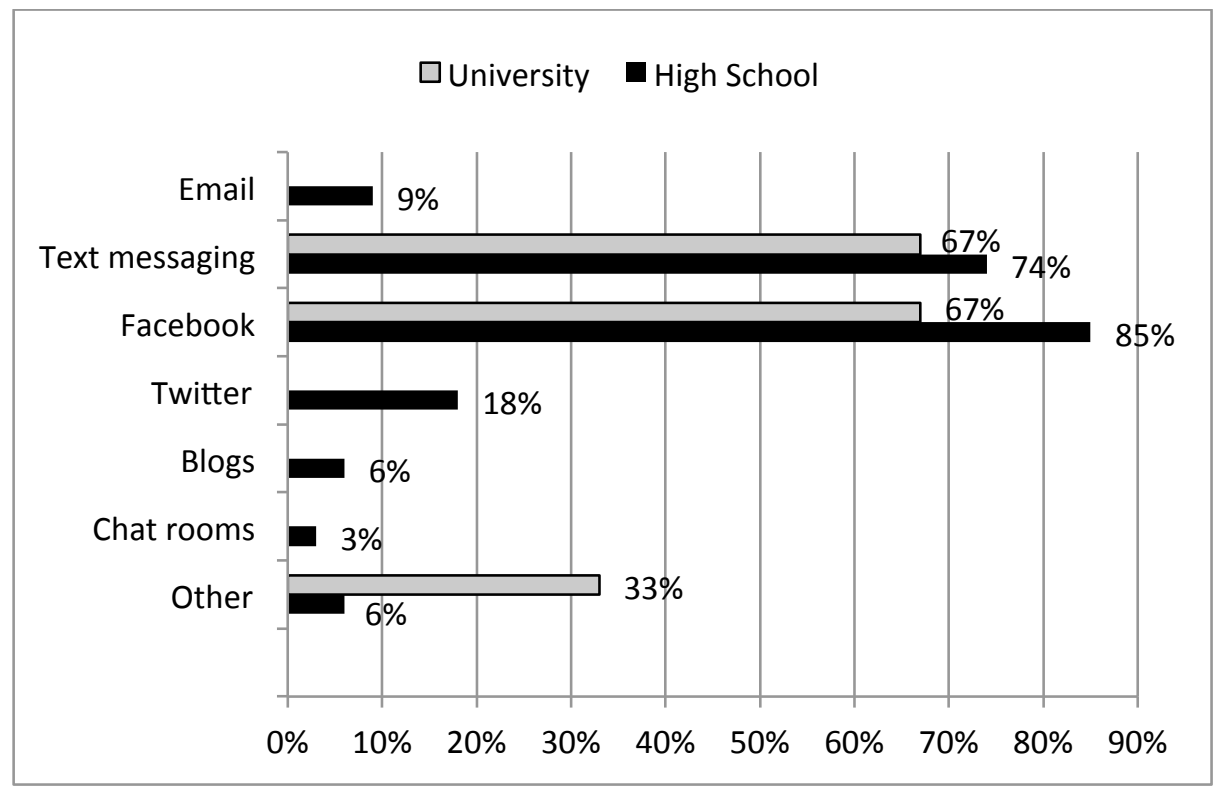

Figure 2. Percentage of university students who have been contacted by a cyberbully via various communication methods, during high school and during time at university.

This trend indicates that Facebook and text messaging have been highly utilized for cyberbullying at the high school level and that they are continuing to be used at the university level. However, as $33 \%$ of university students being cyberbullied currently reported "other" as a means of communication, there may be different technological vehicles for bullying emerging at the university level that this study did not capture.

Participants who responded that they had been a cyberbullying victim were asked if they personally knew the person who was bullying them. One hundred percent of the victims responded that they did know the cyberbully personally. None of the respondents indicated that they did not know the identity of the cyberbully. Further, none of the respondents indicated that the cyberbully was an online acquaintance or other, clearly showing that the respondents all had personal relationships with the cyberbullies. Thirty-seven percent reported that the cyberbully was a friend. Twenty-nine percent indicated that they knew the cyberbully from school and $3 \%$ knew the person from work. Thirty-one percent answered that the cyberbully was a former girlfriend or boyfriend. These results are depicted in Figure 3.

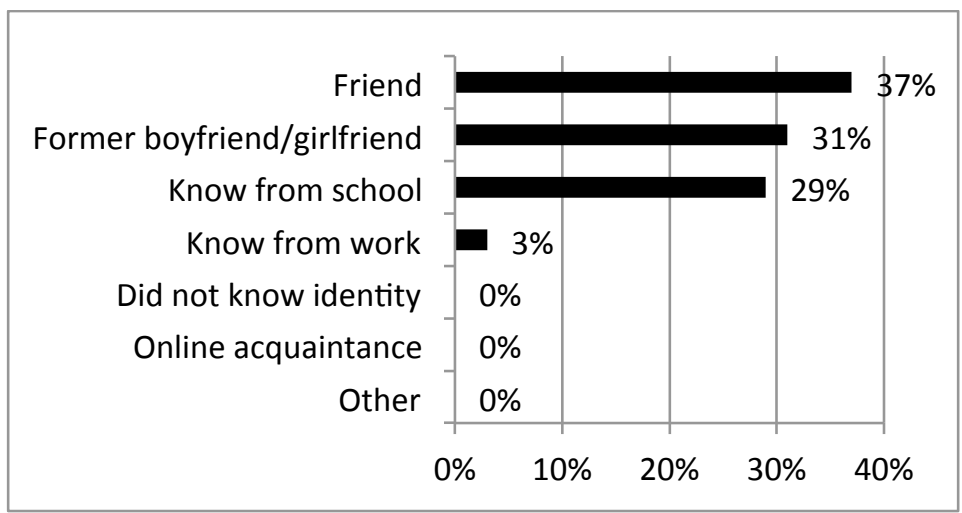

Figure 3. Percentage of student victims of cyberbullying who knew the cyberbully personally in various capacities. 


\section{Issues in Information Systems \\ Volume 14, Issue 2, pp.174-181, 2013}

One of the most common best practices touted to students (and adults) regarding social networking sites, specifically Facebook, is to set privacy controls to the most restrictive setting. This setting is currently "Friends Only," meaning that only those individuals whom you have granted access can see your social profile. Another best practice is to limit those individuals that you accept as "Friends" to people whom you know in real life rather than strangers or acquaintances [10]. While these techniques are useful for protecting private information, in regard to cyberbullying, these controls are largely ineffective. If most cyberbullies are people that you personally know, you may have already granted them access to your social profile. At best, after a cyberbullying incident has occurred, the offending bully can be blocked or removed as a friend, but they will still likely have connections with many of the victims other friends in Facebook, allowing the bullying to go on (and for the victim to hear of it or still see it on the profiles of others).

\section{LIMITATIONS}

The primary limitation of this study was its small sample size, using a convenience sample at a single university. The survey was administered to sections of one core university course normally taken by underclassmen. This caused the age distribution of the sample to be largely skewed toward the 18-20 year old demographic. The researchers encourage future studies to incorporate participants from multiple universities or geographic regions.

\section{CONCLUSIONS}

While the majority of cyberbullying incidents have to date occurred during a student's high school (or primary school) years, there is growing evidence that cyberbullying continues to be a problem for students at the university level. As the use of social networking continues to grow and become a daily facet of university life for communicating with friends, it also clearly presents a vehicle that can easily be used for online harassment. In years past, students who were bullied in high school could expect to escape from the bullying and start fresh in a new college environment. Today, social networking sites enable cyberbullies to follow a student to university and perhaps beyond.

Social networking sites in their current state clearly do not provide any useful capabilities or security mechanisms for preventing cyberbullying incidents. It is currently up to the victims or witnesses of cyberbullying incidents to report online harassment to someone who can help with the situation. Based on the results from the sample surveyed in this study, not enough students are willing to stand up to cyberbullies or report cyberbullying incidents. Education and awareness are keys to solving this problem. A number of anti-bullying programs and cyberbullying awareness programs have been launched across the country, aimed at younger students. Perhaps it is time to address this topic at the university level as well.

In addition, results indicated that there are likely other social networks or communication methods in use at the university level where cyberbullying is occurring that were not directly addressed by this study. Future studies should be directed at identifying and understanding other vehicles for online harassment that were not identified here.

\section{REFERENCES}

1. Consumer Reports (2011 June). Your security: 25 things that cops and crooks say you're doing wrong. Retrieved from http://www.consumerreports.org/cro/magazine-archive/2011/june.june-2011-toc.htm

2. Cornwell, P. (2012, February 23). Cyberbullying remains an issue on campus. USA Today College. Retrieved from http://www.usatodayeducate.com/staging/index.php/ccp/cyberbullying-remains-an-issue-on-campus

3. Harris Interactive (2007 February 28). Teens and cyberbullying. Executive Summary of a Report on Research conducted for the National Crime Prevention Council (NCPC). Retrieved from http:/www.ncpc.org/resources/files/pdf/bullying/Teens\%20and\%20Cyberbullying\%20Research\%20Study.pdf

4. Henson, B., Reyns, B.W., \& Fisher, B.S. (2011). Security in the $21^{\text {st }}$ Century: Examining the link between online social network activity, privacy, and interpersonal victimization. Criminal Justice Review 2011, $36,253$.

5. Hinduja, S. \& Patchin, W. (2010) Cyberbullying: Identification, prevention, and response. Cyberbullying Research Center. Retrieved from http://www.cyberbullying.us/Cyberbullying_Identification_Response_Fact_Sheet 


\section{Issues in Information Systems}

Volume 14, Issue 2, pp.174-181, 2013

6. Lenhardt, A., Madden, M., Smith, A., Purcell, K., Zickuhr, K., \& Raini, L. (2011). Teens kindness and cruelty on social network sites. How teens navigate the new world of "digital citizenship". Pew Research Center's Internet and American Life Project. Retrieved from http://pewinternet.org/Reports/2011/Teens-and-socialmedia.aspx

7. Li, Q. (2010). Cyberbullying in high schools: A study of students' behaviors and beliefs about this new phenomenon. Journal of Aggression, Maltreatment \& Trauma, 19(4), 372-392.

8. Pathcin, J.W. \& Hinduja, S. (2010). Changes in adolescent online social networking behaviors from 2006-2009. Computers and Human Behavior. 25(3).

9. Perez, S. (2010, May 10). More cyberbullying on Facebook, social sites than the rest of the web. Readwrite Social. Retrieved from http;//readwrite.com/2010/05/10/more_cyberbullying_on_facebook_socialsites_than_rest_of web\#feed=/search?keyword=cyberbullying

10. Pinchot, J., Paullet, K. (2012). What's in your profile? Mapping Facebook profile data to personal security questions. Issues in Information Systems, XIII(1), 284-293.

11. Tokunaga, R. (2010). Following you home from school: A critical review and synthesis of research on cyberbullying victimization. Computers in Human Behavior, 26, 277-287.

12. Walker, C.M., Sockman, B.R., \& Koehn, S. (2011, March/April). An exploratory study of cyberbullying with undergraduate university students. Tech Trends. 55(2).

13. Ybarra, M. L., Mitchell, K. J., Wolak, J., \& Finkelhor, D. (2006). Examining characteristics and associated distress related to Internet harassment: Findings from the Second Youth Internet Safety Survey. Pediatrics, 118, e1169-e1177.

14. Zacchili, L.T., and Valerio, C.Y. (2011). The knowledge and prevalence of cyberbullying in a college sample. Journal of Scientific Psychology. Retrieved from http://www.psyencelab.com/images/the_knowledgeand_prevalence_in_a-college_sample.pdf 